\title{
BMJ Open Cancer and non-cancer mortality among French uranium cycle workers: the TRACY cohort
}

\author{
Eric Samson, ${ }^{1}$ Irwin Piot, ${ }^{2}$ Sergey Zhivin, ${ }^{1}$ David B Richardson, ${ }^{1,3}$ Pierre Laroche, ${ }^{4}$ \\ Ana-Paula Serond, ${ }^{4}$ Dominique Laurier, ${ }^{1}$ Olivier Laurent ${ }^{1}$
}

To cite: Samson E, Piot I, Zhivin S, et al. Cancer and non-cancer mortality among French uranium cycle workers: the TRACY cohort. BMJ Open 2016;6:e010316. doi:10.1136/bmjopen-2015010316

- Prepublication history and additional material is available. To view please visit the journal (http://dx.doi.org/ 10.1136/bmjopen-2015010316).

Received 20 October 2015 Revised 4 December 2015 Accepted 22 December 2015

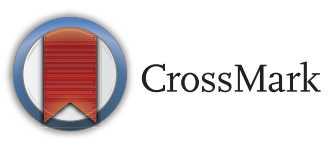

${ }^{1}$ Institut de Radioprotection et de Sureté Nucléaire (IRSN), Laboratoire d'épidémiologie des rayonnements ionisants (PRP-HOM/SRBE/LEPID), Fontenay aux Roses, France ${ }^{2}$ AMAREXIA, Paris, France

${ }^{3}$ Department of

Epidemiology, University of North Carolina, Chapel Hill, North Carolina, USA

${ }^{4}$ AREVA, Direction de la santé, Paris, France

Correspondence to

Eric Samson;

eric.samson@irsn.fr

\section{ABSTRACT}

Objectives: The health effects of internal contamination by radionuclides, and notably by uranium, are poorly characterised. New cohorts of uranium workers are needed to better examine these effects. This paper analyses for the first time the mortality profile of the French cohort of uranium cycle workers. It considers mortality from cancer and non-cancer causes.

Methods: The cohort includes workers employed at least 6 months between 1958 and 2006 in French companies involved in the production of nuclear fuel. Vital status and causes of death were collected from French national registries. Workers were followed-up from 1 January 1968 to 31 December 2008. Standardised mortality ratios (SMRs) were computed based on mortality rates for the French general population.

Results: The cohort includes 12649 workers (88\% men). The average length of follow-up is 27 years and the mean age at the end of the study is 60 years. Large mortality deficits are observed for non-cancer causes of death such as non-cancer respiratory diseases (SMR $=0.51$ (0.41 to 0.63)) and circulatory diseases $(S M R=0.68$ (0.62 to 0.74$))$. A mortality deficit of lower magnitude is also observed for all cancers combined (SMR (95\% Cl): 0.76 (0.71 to 0.81$)$ ). Pleural mesothelioma is elevated (SMR=2.04 (1.19 to 3.27)).

Conclusions: A healthy worker effect is observed in this new cohort of workers involved in the uranium cycle. Collection of individual information on internal uranium exposure as well as other risk factors is underway, to allow for the investigation of uraniumrelated risks.

\section{INTRODUCTION}

Ionising radiation is an established carcinogen $^{1}$ and its effects on cancer risk are reasonably well understood and quantified, at least at high doses (>100 mGy) and dose rates $(>5 \mathrm{mGy} / \mathrm{h}) .^{2}$ By comparison, cancer risks associated with internal exposures resulting from the incorporation of radionuclides into the body are less well quantified. ${ }^{3}$ This is a

\section{Strengths and limitations of this study}

- TRACY (TRAvailleurs du CYcle) is a new and rare cohort of uranium fuel cycle workers.

- Almost 13000 workers have been included from 1958 to 2006.

- Only $1 \%$ of workers were lost to follow-up.

- In France, individual causes of death are only available since 1968.

- Further work is ongoing to allow for the detailed investigation of uranium-related risk.

major issue for radiation protection since internal exposures are responsible for a large portion of the population's collective effective dose due to exposure to naturally occurring radionuclides, such as radon, as well as medical diagnostic and occupational sources of internal exposures. ${ }^{1}$ In addition, there is growing interest in health effects other than cancer following exposure to low doses of ionising radiation (eg, diseases of the circulatory system $^{4}$ ), notably following internal exposure. $^{5}$

With the exception of studies on radon, relatively few recent epidemiological studies have directly quantified the health effects of internal contamination in populations chronically exposed to radionuclides. ${ }^{6-9}$ As a result, the International Commission on Radiological Protection, which elaborates and periodically updates international radiation protection recommendations, had to estimate the radiation-related risks of internal exposure to radionuclides, such as uranium, by combining epidemiological evidence from external exposure situations with that from experimental studies on the biological effects of internal emitters. ${ }^{10}$ It would be preferable to have direct epidemiological evidence regarding the effects of internal exposure to such radionuclides. There is, therefore, the need for further studies of populations exposed to internal emitters, to help assess 
the adequacy of current radiation protection standards with respect to internal exposure. ${ }^{5}$

In addition to its radiological toxicity, uranium, as a heavy metal, may exhibit chemical toxicity. This chemical toxicity has been demonstrated on the kidney and brain, ${ }^{11}$ and might possibly extend to other organs. Therefore, even if models used to predict radiation-induced health effects from uranium exposure proved strictly adequate, additional data would be needed to characterise the total (ie, radiological plus chemical) health effects of uranium exposure in humans. This further justifies the need to directly quantify these effects in exposed populations.

Cohorts of workers involved in the uranium fuel cycle are of interest to study the risks associated with internal contamination by uranium because many workers have been regularly monitored for internal exposure via bioassay analyses. ${ }^{5}$ However, few such cohorts have been set up. ${ }^{12-18}$ A recent review concluded that, so far, studies based on these cohorts have not provided reliable evidence on the potential health risks associated with uranium exposure, notably because of insufficient statistical power. ${ }^{19}$ Pooling existing large cohorts of uranium workers and setting up new ones is clearly needed to improve the knowledge of the health effects of uranium exposure. $^{20}$

France has operated a complete nuclear fuel production cycle since the 1960s. The French cohort of workers employed in the nuclear fuel production cycle (TRACY, TRAvailleurs du CYcle) was set up to assess the risk of cancer and non-cancer mortality related to internal exposure to uranium. Pilot studies were successfully conducted in specific subsets of this large cohort. ${ }^{21} 22$ The reconstitution of exposure data in the entire TRACY cohort is underway.

The aim of the current investigation was to describe mortality among the uranium workers in this new large cohort, by comparison with the general population.

\section{MATERIAL AND METHODS}

\section{Study design}

TRACY is a retrospective cohort designed to study the mortality of workers involved in the French uranium fuel cycle. As will be detailed below, occupational data were collected from 2009 to 2013 and cover a period spanning from 1958 to 2006, whereas mortality data cover a period spanning from 1968 to 2008 .

\section{Study population}

The companies included in this study cover different steps of the nuclear fuel production cycle in France (figure 1): purification of concentrated natural uranium, conversion to uranium hexafluoride, enrichment by gaseous diffusion, fuel manufacturing and other activities such as storage (depleted and reprocessed uranium), and decontamination (waste and effluents). Companies involved in uranium mining and milling are not included, nor are companies that are end users of the nuclear fuel (eg, those involved in electricity production). The companies included and their respective main activities are presented in online supplementary appendix table 1 . TRACY is complementary to the French uranium miners cohort ${ }^{23}$ and to the French nuclear workers cohort, designed to study the association between external chronic exposure to radiation and mortality ${ }^{24}$ whereas the main focus of TRACY is internal contamination by uranium. The overlaps between TRACY and the French cohorts of uranium miners and nuclear workers include 158 and 5057 participants, respectively.

Workers included in the cohort had to be employed for at least 6 months as members of the permanent staff of selected companies between 1958 and 2006. Personal identifiers and work histories were provided by the administrative departments of each company, either on paper or electronic files. The files were computerised whenever needed, validated and merged. Transfers from one company to another were taken into account to avoid duplicate counts and accurately reconstruct time spent in the different companies included in the TRACY cohort where workers were employed. The detailed characterisation of workplaces and job titles is a long-term task for this large cohort and is still underway.

The date of start of employment was defined as the earliest one if several periods of employment were recorded. The date of end of employment, whatever the reason (retirement, resignation, dismissal, job transfer to a company not included in the study), was identified from the last recorded period of employment. For workers still employed on 31 December 2006, the end of employment was set to that date.

\section{Follow-up, vital status and causes of death}

For each worker, follow-up of vital status began on the most recent date among the following: date of initial employment plus 6 months, or 1 January 1968. The lower bound of the follow-up period had to be set to that date since the national registry that provides causes of death information in France (CépiDC-Inserm) can deliver no individual data before 1968. Among the cohort members who began working before 1968, 53 had died or would have been lost to follow-up before 1968 and could not be included in the mortality study. The date of end of follow-up was defined as the earliest among the following: date of death, last information date (for workers lost to follow-up) and 31 December 2008. Workers' vital status and the date of death for workers who died were obtained from the National Vital Status Registry (Répertoire National d'Identication des Personnes Physiques) by file matching on name, surnames, gender, date and place of birth. To avoid erroneous linkages, only workers with one possible match with the registry were considered as identified. Causes of death coded according to the International Classification of Diseases (ICD, V.8 for period 1968-1978, V.9 for 


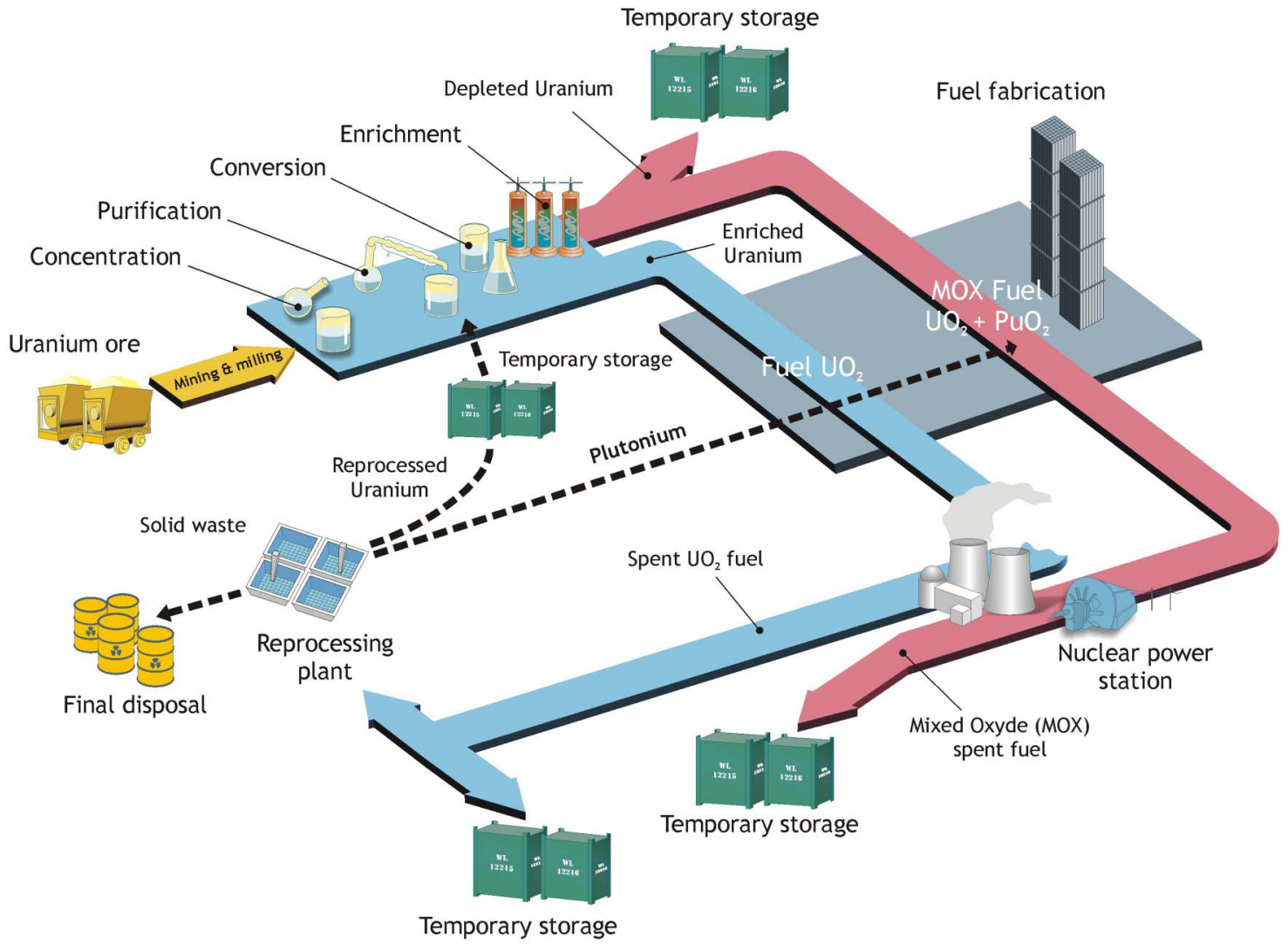

Figure 1 Simplified diagram describing the French uranium fuel cycle.

1979-1999 and V.10 for period 2000-2008, see online supplementary appendix table 2) and corresponding labels were obtained by file matching on gender, date and place of birth and date and place of death with the French national mortality registry (CépiDC-Inserm). In case of multiple matches, no causes could be obtained for these workers.

\section{Statistical analysis}

Mortality rates were compared with those in the French general population (also obtained from CépiDC-Inserm) by computing standardised mortality ratios (SMRs), therefore controlling for potential confounders: sex, age (categorised as follows: 15-19, $20-24, \ldots, 80-84, \geq 85$ years) and calendar period (categorised as follows: 1968-1972, 1973-1977,..., 1998-2002, 2003-2008) as classically performed for such analyses. ${ }^{25}$ Using the Poisson exact method, confidence intervals (95\% CIs) were calculated. ${ }^{26}$ This was performed for specific causes of death (eg, cancer of specific organs or tissues) or broader groupings of causes (eg, all cancers, all circulatory diseases, cancer sites potentially associated with smoking). ${ }^{27}$ Online supplementary appendix table 2 provides the definition and corresponding ICD codes of all causes of death considered. For the primary analysis, SMRs were computed for men and women grouped together. The 'All causes' group included workers with non-identified causes of death. Results were reported only for causes of death with at least five cases observed across the whole cohort.

Supplementary analyses were conducted for broad groupings of causes of death (all causes, cancers, diseases of the circulatory system and respiratory diseases) to examine the evolution of SMRs according to time since hire (categorised as follows: <25, 25-39, $\geq 40$ years), time since end of employment (categorised as follows: $<10,10-19, \geq 20$ years), total duration of employment (categorised as follows: <10, 10-24, $\geq 25$ years) and attained age (categorised as follows: $<50$, $50-65, \geq 66$ years). ${ }^{28}$ Further analyses were conducted to estimate SMRs among men and women separately. We also conducted supplementary analyses according to groupings of companies involved in the three main steps of the uranium cycle (conversion, enrichment by gaseous diffusion and manufacturing of oxide fuel), in two ways. First, we considered workers involved in only one grouping of companies covering a specific step (therefore not allowing for overlap between population subgroups, by excluding workers who got involved during their careers in several groupings of companies covering different steps) and second, considering workers involved in at least one of these grouping of companies (therefore allowing for overlap between the population groupings analysed). For conversion, we considered workers employed by Comurhex (Malvési and Pierrelatte plants). For enrichment, we considered a specific subcohort extract from the TRACY cohort with 
workers involved in both military and civil enrichment. ${ }^{29}$ Workers employed by FBFC-CERCA (Romans sur Isère and Pierrelatte plants) constituted the oxide fuel manufacturing grouping.

All analyses were conducted using SAS software, V.9.2 (Cary, North Carolina, USA).

The protocol of this study was validated by the French Data Protection Authority (CNIL), agreement number DR-2012-611.

\section{RESULTS}

The inclusion process (summarised in online supplementary appendix figure 1) started from a base of 21143 potentially eligible workers. After removal of duplicates (3063 tuples) and exclusion of workers who did not match the eligibility criteria, 12713 workers were confirmed to be eligible and included in the study. After further exclusion of one worker with identifiers not sufficient to match with national files (place of birth unknown) and of workers either dead or who would have been lost to follow-up before 1968, the mortality analysis was performed on 12649 workers.

Workers excluded were permanent status workers who cumulated less than 6 months of employment $(\mathrm{N}=641)$, trainees $(\mathrm{N}=2561)$, short-term workers $(\mathrm{N}=2036)$ and others special contracts (military service, scientific advisor, $\mathrm{N}=129$ ). Excluded workers cumulated an average duration of work of 0.50 years. Contractors were not mentioned in the employee personnel files and therefore could not be considered.

The main characteristics of the cohort are presented in table 1. Among the 12649 workers included, 88\% were males. The cohort cumulated 342258 person-years of observation. The mean duration of follow-up was 27 years. The mean age at the end of the study was 60 years. The mean age at hire was 30 years and 49 years at the end of employment. The mean duration of employment was 19 years. At the end of the follow-up, $82 \%$ of workers were still alive, $17 \%$ were deceased and $1 \%$ were lost to follow-up. Underlying cause of death was identified for $99 \%$ of the 2130 deaths recorded.

SMRs are presented in table 2 for the whole cohort. A substantial mortality deficit was observed for all-cause mortality compared to expectation based on French national rates (SMR $0.65 ; 95 \%$ CI 0.62 to 0.68 ; $\mathrm{n}=2130$ ).

There was a substantial deficit in mortality for most major categories of non-malignant diseases. All noncancer mortality was in $42 \%$ deficit (SMR $0.58 ; 95 \%$ CI 0.55 to $0.62, \mathrm{n}=1012$ ). There were substantial deficits in deaths due to non-malignant respiratory diseases (SMR $0.51 ; 95 \%$ CI 0.41 to $0.63, \mathrm{n}=88)$, circulatory diseases (SMR 0.68; 95\% CI 0.62 to $0.74, \mathrm{n}=540$ ), non-malignant renal diseases (SMR 0.66; 95\% CI 0.39 to $1.06, \mathrm{n}=17$ ) and external causes of death including suicides and accidents (SMR 0.54; 95\% CI 0.46 to $0.62, \mathrm{n}=186$ ).

For deaths due to all malignant diseases grouped together, there was also a deficit in the entire cohort although less pronounced than for most non-malignant categories of cause of death. Overall, cancer mortality was in $24 \%$ deficit (SMR 0.76; 95\% CI 0.71 to 0.81 , $\mathrm{n}=912$ ). However, a twofold excess was observed for pleural mesothelioma (SMR 2.04; 95\% CI 1.19 to 3.27; $\mathrm{n}=17$ ) and non-significant excesses were observed for other cancers: pancreas (SMR 1.05; 95\% CI 0.79 to 1.38 ,

Table 1 Description of the TRACY cohort

\begin{tabular}{|c|c|c|c|c|c|c|}
\hline & \multicolumn{2}{|l|}{ Men } & \multicolumn{2}{|l|}{ Women } & \multicolumn{2}{|l|}{ All } \\
\hline & Number & Per cent & Number & Per cent & Number & Per cent \\
\hline All workers & 11122 & 87.9 & 1527 & 12.1 & 12649 & 100 \\
\hline Person-years & 303606 & 88.7 & 38652 & 11.3 & 342258 & 100 \\
\hline \multicolumn{7}{|l|}{ Vital status on 31 December 2008} \\
\hline Alive & 8992 & 80.9 & 1386 & 90.8 & 10378 & 82.1 \\
\hline Still employed & 3937 & 35.4 & 620 & 40,6 & 4557 & 36.0 \\
\hline Deceased & 2028 & 18.2 & 102 & 6.7 & 2130 & 16.8 \\
\hline With identified causes & 2009 & 99.1 & 102 & 100 & 2111 & 16.7 \\
\hline \multirow[t]{2}{*}{ Lost to follow-up } & 102 & 0.9 & 39 & 2.5 & 141 & 1.1 \\
\hline & Median & Mean & Median & Mean & Median & Mean \\
\hline Year of birth & 1943 & 1945 & 1949 & 1951 & 1944 & 1946 \\
\hline Age at death & 67.8 & 66.4 & 60.9 & 62.2 & 67.5 & 66.2 \\
\hline Age at hiring & 28.1 & 30.5 & 26.4 & 28.9 & 27.9 & 30.3 \\
\hline Age at end of employment (All) & 53.8 & 49.8 & 47.5 & 45.5 & 53.1 & 49.3 \\
\hline Still employed & 49.0 & 47.5 & 47.3 & 46.0 & 48.7 & 47.3 \\
\hline Not employed anymore & 56.9 & 51.1 & 48.4 & 45.1 & 56.7 & 50.4 \\
\hline Duration of employment in years & 19.9 & 19.4 & 14.3 & 16.6 & 19.3 & 19.0 \\
\hline Age at beginning of follow-up & 31.2 & 33.2 & 29.0 & 31.1 & 31.0 & 32.9 \\
\hline Age at end of follow-up & 61.1 & 60.5 & 56.3 & 56.5 & 60.6 & 60.0 \\
\hline Duration of follow-up in years & 28.3 & 27.3 & 25.5 & 25.3 & 27.9 & 27.1 \\
\hline
\end{tabular}


Table 2 SMRs in the TRACY cohort (1968-2008)*

\begin{tabular}{|c|c|c|c|}
\hline Cause of death & $\begin{array}{l}\text { Observed number } \\
\text { of deaths }\end{array}$ & SMR & $95 \% \mathrm{Cl}$ \\
\hline All causes & 2130 & 0.65 & $(0.62-0.68)$ \\
\hline Non-cancers diseases & 1013 & 0.58 & $(0.55-0.62)$ \\
\hline Diseases of the circulatory system & 540 & 0.68 & $(0.62-0.74)$ \\
\hline Hypertensive diseases & 15 & 0.56 & $(0.31-0.93)$ \\
\hline Ischaemic heart diseases & 212 & 0.71 & $(0.62-0.81)$ \\
\hline Cerebrovascular diseases & 130 & 0.75 & $(0.63-0.90)$ \\
\hline Other and unspecified disorders of the circulatory system & 183 & 0.61 & $(0.52-0.71)$ \\
\hline Respiratory diseases & 88 & 0.51 & (0.41-0.63) \\
\hline Diseases of the digestive system (other than cirrhosis) & 48 & 0.58 & $(0.43-0.77)$ \\
\hline Diseases of the genitourinary system & 23 & 0.70 & $(0.44-1.05)$ \\
\hline Renal diseases & 17 & 0.66 & (0.39-1.06) \\
\hline \multicolumn{4}{|l|}{ Other non-cancers diseases } \\
\hline Non-malignant tumours of central nervous system and sense organs & 10 & 0.77 & $(0.37-1.42)$ \\
\hline Endocrine, nutritional and metabolic diseases & 47 & 0.67 & (0.49-0.89) \\
\hline Diseases of the blood and blood-forming organs & 7 & 0.63 & $(0.25-1.30)$ \\
\hline Cirrhosis, psychosis and other diseases due-alcohol & 48 & 0.27 & $(0.20-0.35)$ \\
\hline Non-tumoural diseases of central nervous system and sense organs & 68 & 0.83 & $(0.64-1.05)$ \\
\hline Diseases of the skin & 5 & 1.14 & $(0.37-2.67)$ \\
\hline Diseases of the musculoskeletal system and connective tissue & 8 & 0.74 & $(0.32-1.46)$ \\
\hline Other & 121 & 0.43 & $(0.35-0.51)$ \\
\hline All cancers & 912 & 0.76 & $(0.71-0.81)$ \\
\hline Smoking-related cancers & 495 & 0.68 & $(0.62-0.75)$ \\
\hline Mouth & 13 & 0.46 & $(0.25-0.79)$ \\
\hline Pharynx & 28 & 0.57 & (0.38-0.82) \\
\hline Oesophagus & 33 & 0.52 & $(0.36-0.73)$ \\
\hline Stomach & 29 & 0.64 & (0.43-0.92) \\
\hline Liver & 31 & 0.65 & (0.44-0.92) \\
\hline Pancreas & 53 & 1.05 & (0.79-1.38) \\
\hline Nasal cavity, sinus and middle ear & 5 & 0.24 & $(0.08-0.57)$ \\
\hline Larynx & 20 & 0.49 & $(0.30-0.75)$ \\
\hline Lung & 217 & 0.73 & (0.64-0.83) \\
\hline Bladder & 26 & 0.69 & $(0.45-1.01)$ \\
\hline Kidney & 24 & 0.84 & $(0.54-1.24)$ \\
\hline Non-smoking-related cancers & 358 & 0.87 & (0.79-0.97) \\
\hline Colon & 60 & 0.78 & (0.60-1.01) \\
\hline Rectum & 26 & 0.87 & $(0.57-1.28)$ \\
\hline Gallbladder and bile ducts & 7 & 0.98 & $(0.39-2.01)$ \\
\hline Pleura & 17 & 2.04 & (1.19-3.27) \\
\hline Melanoma & 15 & 1.60 & $(0.90-2.64)$ \\
\hline Breast & 20 & 1.32 & $(0.81-2.04)$ \\
\hline Prostate & 71 & 0.94 & (0.74-1.19) \\
\hline Brain and central nervous system & 32 & 1.36 & (0.93-1.91) \\
\hline Other non-smoking-related cancers & 106 & 0.69 & $(0.57-0.84)$ \\
\hline Haematological and lymphatic malignancies & 74 & 0.96 & $(0.75-1.20)$ \\
\hline Leukaemia & 33 & 1.00 & $(0.69-1.40)$ \\
\hline Lymphocytic leukaemia & 12 & 1.38 & (0.71-2.42) \\
\hline Chronic lymphocytic leukaemia (CLL) & 8 & 1.28 & (0.55-2.52) \\
\hline Myeloid leukaemia & 15 & 1.06 & $(0.59-1.74)$ \\
\hline Acute myeloid leukaemia & 10 & 1.22 & $(0.58-2.24)$ \\
\hline Other leukaemia & 6 & 0.59 & $(0.22-1.28)$ \\
\hline Leukaemia without CLL & 25 & 0.93 & (0.60-1.38) \\
\hline Multiple myeloma & 18 & 1.29 & $(0.77-2.05)$ \\
\hline Non-Hodgkin's lymphoma & 23 & 0.86 & $(0.55-1.30)$ \\
\hline External causes & 186 & 0.54 & (0.46-0.62) \\
\hline Suicides & 77 & 0.66 & (0.52-0.82) \\
\hline Accidents & 98 & 0.47 & $(0.39-0.58)$ \\
\hline Other external causes & 11 & 0.49 & (0.24-0.87) \\
\hline
\end{tabular}

${ }^{*}$ For causes of deaths with at least 5 cases observed.

SMRs, standardised mortality ratios; TRACY, TRAvailleurs du CYcle. 
$\mathrm{n}=53$ ), skin melanoma (SMR 1.60; $95 \%$ CI 0.90 to 2.64, $\mathrm{n}=15$ ), breast (all observed cases being among women, see online supplementary appendix table 3; SMR 1.53; $95 \%$ CI 0.94 to $2.37 ; \mathrm{n}=20$ ), brain and central nervous system (SMR 1.36; 95\% CI 0.93 to $1.91, \mathrm{n}=32$ ), lymphocytic (SMR 1.38; 95\% CI 0.71 to $2.42, \mathrm{n}=12$ ) and myeloid (SMR 1.06; $95 \%$ CI 0.59 to $1.74, \mathrm{n}=15$ ) leukaemia and multiple myeloma (SMR 1.29; $95 \%$ CI 0.77 to
$2.05, \mathrm{n}=18)$. In contrast, there was a substantial deficit in deaths due to smoking-related cancers (SMR 0.68; 95\% CI 0.62 to $0.75, \mathrm{n}=495$ ).

SMRs for cancer diseases tended to increase with time since hire, time since end of employment and attained age (table 3). Twenty years after the end of employment, the risk of cancer mortality is not significantly different from that in the general population, whereas it remains

Table 3 SMRs and 95\% Cl in the TRACY cohort (1968-2008), by time since hire, time since end of employment, duration of employment and age reached, for broad groupings of causes of death

\begin{tabular}{|c|c|c|c|c|c|c|c|c|c|}
\hline \multicolumn{10}{|c|}{ Time since hire } \\
\hline \multirow[b]{2}{*}{$\begin{array}{l}\text { Cause of } \\
\text { death }\end{array}$} & \multicolumn{3}{|c|}{ Less than 25 years } & \multicolumn{3}{|l|}{ 25-39 years } & \multicolumn{3}{|c|}{40 years or more } \\
\hline & $\begin{array}{l}\text { Observed } \\
\text { Number of } \\
\text { deaths }\end{array}$ & SMR & $95 \% \mathrm{Cl}$ & $\begin{array}{l}\text { Observed } \\
\text { Number of } \\
\text { deaths }\end{array}$ & SMR & $95 \% \mathrm{Cl}$ & $\begin{array}{l}\text { Observed } \\
\text { Number of } \\
\text { deaths }\end{array}$ & SMR & $95 \% \mathrm{Cl}$ \\
\hline All causes & 633 & 0.54 & (0.50 to 0.58$)$ & 967 & 0.70 & (0.66 to 0.75$)$ & 530 & 0.73 & (0.66 to 0.79$)$ \\
\hline All cancers & 242 & 0.64 & (0.57 to 0.73 ) & 457 & 0.81 & (0.74 to 0.89 ) & 213 & 0.82 & (0.71 to 0.93$)$ \\
\hline $\begin{array}{l}\text { Circulatory } \\
\text { diseases }\end{array}$ & 160 & 0.67 & (0.57 to 0.79$)$ & 235 & 0.66 & (0.58 to 0.75 ) & 145 & 0.71 & (0.60 to 0.83 ) \\
\hline $\begin{array}{l}\text { Respiratory } \\
\text { diseases }\end{array}$ & 14 & 0.33 & (0.18 to 0.55$)$ & 48 & 0.61 & (0.45 to 0.81$)$ & 26 & 0.50 & (0.33 to 0.73 ) \\
\hline
\end{tabular}

\section{Time since end of employment}

\begin{tabular}{|c|c|c|c|c|c|c|c|c|c|}
\hline \multirow[b]{2}{*}{$\begin{array}{l}\text { Cause of } \\
\text { death }\end{array}$} & \multicolumn{3}{|c|}{ Less than 10 years } & \multicolumn{3}{|l|}{ 10-19 years } & \multicolumn{3}{|c|}{20 years or more } \\
\hline & $\begin{array}{l}\text { Observed } \\
\text { Number of } \\
\text { deaths }\end{array}$ & SMR & $95 \% \mathrm{Cl}$ & $\begin{array}{l}\text { Observed } \\
\text { Number of } \\
\text { deaths }\end{array}$ & SMR & $95 \% \mathrm{Cl}$ & $\begin{array}{l}\text { Observed } \\
\text { Number of } \\
\text { deaths }\end{array}$ & SMR & $95 \% \mathrm{Cl}$ \\
\hline All causes & 945 & 0.56 & (0.52 to 0.59$)$ & 591 & 0.74 & (0.68 to 0.80$)$ & 594 & 0.75 & (0.70 to 0.82$)$ \\
\hline All cancers & 430 & 0.68 & (0.62 to 0.75$)$ & 243 & 0.81 & (0.71 to 0.92$)$ & 239 & 0.89 & (0.79 to 1.02$)$ \\
\hline $\begin{array}{l}\text { Circulatory } \\
\text { diseases }\end{array}$ & 217 & 0.62 & (0.54 to 0.71$)$ & 162 & 0.72 & (0.61 to 0.84$)$ & 161 & 0.72 & (0.61 to 0.84$)$ \\
\hline Respiratory & 16 & 0.25 & (0.14 to 0.41$)$ & 39 & 0.75 & (0.53 to 1.02$)$ & 33 & 0.58 & (0.40 to 0.81$)$ \\
\hline
\end{tabular}

diseases

\section{Duration of employment}

\begin{tabular}{|c|c|c|c|c|c|c|c|c|c|}
\hline \multirow[b]{2}{*}{$\begin{array}{l}\text { Cause of } \\
\text { death }\end{array}$} & \multicolumn{3}{|c|}{ Less than 10 years } & \multicolumn{3}{|l|}{ 10-24 years } & \multicolumn{3}{|c|}{25 years or more } \\
\hline & $\begin{array}{l}\text { Observed } \\
\text { Number of } \\
\text { deaths }\end{array}$ & SMR & $95 \% \mathrm{Cl}$ & $\begin{array}{l}\text { Observed } \\
\text { Number of } \\
\text { deaths }\end{array}$ & SMR & $95 \% \mathrm{Cl}$ & $\begin{array}{l}\text { Observed } \\
\text { Number of } \\
\text { deaths }\end{array}$ & SMR & $95 \% \mathrm{Cl}$ \\
\hline All causes & 575 & 0.66 & (0.61 to 0.71$)$ & 1073 & 0.67 & (0.63 to 0.71$)$ & 482 & 0.60 & (0.55 to 0.66$)$ \\
\hline All cancers & 243 & 0.82 & (0.72 to 0.93$)$ & 426 & 0.78 & (0.70 to 0.85$)$ & 243 & 0.69 & (0.61 to 0.78$)$ \\
\hline $\begin{array}{l}\text { Circulatory } \\
\text { diseases }\end{array}$ & 126 & 0.66 & (0.55 to 0.79$)$ & 314 & 0.73 & (0.65 to 0.82$)$ & 100 & 0.56 & $(0.45$ to 0.68$)$ \\
\hline $\begin{array}{l}\text { Respiratory } \\
\text { diseases }\end{array}$ & 25 & 0.62 & (0.40 to 0.92$)$ & 48 & 0.50 & (0.37 to 0.67 ) & 15 & 0.40 & (0.22 to 0.66$)$ \\
\hline \multicolumn{10}{|l|}{ Attained age } \\
\hline & \multicolumn{3}{|c|}{ Less than 50 years old } & \multicolumn{3}{|c|}{$50-65$ years old } & \multicolumn{3}{|c|}{66 years old or more } \\
\hline $\begin{array}{l}\text { Cause of } \\
\text { death }\end{array}$ & $\begin{array}{l}\text { Observed } \\
\text { Number of } \\
\text { deaths }\end{array}$ & SMR & $95 \% \mathrm{Cl}$ & $\begin{array}{l}\text { Observed } \\
\text { Number of } \\
\text { deaths }\end{array}$ & SMR & $95 \% \mathrm{Cl}$ & $\begin{array}{l}\text { Observed } \\
\text { Number of } \\
\text { deaths }\end{array}$ & SMR & $95 \% \mathrm{Cl}$ \\
\hline All causes & 269 & 0.50 & (0.44 to 0.56$)$ & 662 & 0.56 & (0.52 to 0.61$)$ & 1199 & 0.77 & (0.72 to 0.81$)$ \\
\hline All cancers & 78 & 0.60 & (0.48 to 0.75$)$ & 358 & 0.70 & (0.63 to 0.77 ) & 476 & 0.86 & (0.78 to 0.94$)$ \\
\hline $\begin{array}{l}\text { Circulatory } \\
\text { diseases }\end{array}$ & 52 & 0.67 & (0.50 to 0.87 ) & 147 & 0.59 & (0.50 to 0.69 ) & 341 & 0.73 & (0.65 to 0.81$)$ \\
\hline $\begin{array}{l}\text { Respiratory } \\
\text { diseases }\end{array}$ & 5 & 0.38 & (0.12 to 0.88$)$ & 13 & 0.29 & (0.16 to 0.50$)$ & 70 & 0.61 & (0.48 to 0.77$)$ \\
\hline
\end{tabular}


significantly lower for circulatory and respiratory diseases. No clear trend was observed according to the duration of employment for mortality from all causes and from circulatory diseases. However, there was evidence of a decreasing trend along with duration of employment for mortality from cancer and respiratory diseases. For all broad groupings of causes of death, the lowest SMRs were observed in workers with the longest duration of employment (table 3).

Significant deficits in all-cause and non-cancer mortality were observed for both genders (see online supplementary appendix tables 3 and 4). In women, non-significant excesses of cancer mortality were observed. However, CIs were very wide due to the lower number of women (and, therefore, of deaths observed in these women) in the cohort (see online supplementary appendix table 3). In men, a significant deficit in mortality from all cancers was also observed and results were overall comparable to those in the entire cohort (see online supplementary appendix table 4).

For all groupings of causes of death considered, we observed no difference in mortality patterns according to groupings of companies involved in the main three steps of the cycle, regardless of the way the groupings were defined (see online supplementary appendix table 5).

\section{DISCUSSION}

This is the first mortality study conducted in this new cohort of uranium cycle workers, which is one of the largest of its kind. A healthy worker effect (HWE) is observed. It is especially strong for major groups of noncancer diseases, including circulatory and non-cancer respiratory diseases. For all cancers grouped together, a healthy worker effect is also observed overall, but is less marked than for non-cancer diseases. No deficit in cancer mortality is observed in workers 20 years or older after the end of employment, or in women. A significant excess of malignant pleural mesothelioma is observed and non-significant excesses are observed for a few other specific cancer sites.

\section{Mortality profile}

The HWE is often observed in occupational cohorts, including nuclear worker cohorts. ${ }^{24} 2528$ It partly results from the selection of healthier people at hiring (referred to as the 'healthy hire effect', ${ }^{28}$ which tends to shrink with time since hire) and from other selection effects making the healthiest individuals more likely to be retained in the workforce than individuals with poorer health (referred to as the 'healthy survivor effect $^{28}$ and reflected by the fact that workers with the longest duration of employment exhibit the lowest SMRs). The regular health surveillance provided by occupational medicine services as well as other factors such as work-related physical activity are also suspected to contribute to the healthy survivor effect. As time since the end of employment goes by, the mortality profile of workers tends to reach that of the general population. These patterns were observed in the TRACY cohort, in agreement with previous literature. ${ }^{24} 2528$ Methods have been proposed to calculate adjusted SMRs as a complement to the traditional SMR which may facilitate interpretation of findings in spite of comparability issues due to the HWE; a recent example of such an approach draws on methods developed for the use of negative control outcomes for bias reduction. ${ }^{30}$ Such methods have not been applied in the current paper, however, since it is difficult to define a relevant negative control outcome for a population of workers exposed to uranium. In spite of the aforementioned limitations resulting from the HWE, comparisons of mortality profiles of occupational cohorts with those of general populations have been considered to be a useful approach and, therefore, have been widely used in occupational epidemiology. 18253132

Importantly, the observed HWE does not mean that no case attributable to uranium or to other sources of radiation occurred in the TRACY cohort. The present analysis provides a simple but informative picture of the general level of risk in this cohort of workers of the uranium fuel cycle, through a comparison with the general population. The risk in the cohort is not only influenced by uranium and other radiation exposures but also by the levels of exposure to other risk factors. For instance, the SMR for the grouping of cancer sites that may be caused by smoking ${ }^{27}$ is low in the TRACY cohort. This suggests a lower level of exposure to smoking in this cohort than in the general population.

Conversely, we observed an excess of pleural mesothelioma. We acknowledge that the diagnosis and ascertainment of mesothelioma on death certificates has been problematic until at least the early 1990s. ${ }^{33}$ This limitation applied both to the TRACY cohort and to the comparison group, the French general population. ${ }^{34}$ The ascertainment of mesothelioma improved with the introduction of ICD $10,{ }^{35}$ which was used since year 2000 for French death certificates. Excesses of pleural mesothelioma were also reported in most other nuclear worker cohort studies. ${ }^{36}$ An excess risk was also observed in the French cohort of nuclear workers, designed to study the effects of external radiation exposure (based on 36 deaths), ${ }^{37}$ but it has to be noted that these two results are not independent, due to partial overlap of the two cohorts, concerning workers from AREVA NC and CEA Pierrelatte plant (10 deaths in common, among 5057 workers included in both cohorts). Evidence for an association between exposure to ionising radiation and pleural mesothelioma is weak, however, ${ }^{36}$ and, to the best of our knowledge, no association between uranium exposure and mesothelioma has ever been reported. By contrast, asbestos exposure is a strong risk factor for this disease, and has been known to occur in companies included in TRACY, ${ }^{38}$ as well as in other companies in which some workers were employed before joining the nuclear fuel industry. This 
might contribute to the excess of malignant pleural mesothelioma observed in this cohort.

Non-significant excesses were observed for a few cancer sites in TRACY. For pancreas cancer, nonsignificantly positive SMRs were also observed in several other cohorts of uranium workers (including uranium millers) ${ }^{14173940}$ but not in all ${ }^{15} 18313241$ (see online supplementary appendix table 6).

For all leukaemias grouped together, patterns are not consistent across cohorts either. A proper comparison by leukaemia subtype is hampered by the inhomogeneous sets of subtypes for which results were reported in available studies. However, non-significant excesses of multiple myeloma ${ }^{17} 3942$ or myeloma ${ }^{32}$ were reported in most cohorts that evaluated this outcome (see online supplementary appendix table 6 ).

Non-significant excesses of cancers of the brain and central nervous system were reported in most cohorts of uranium workers. ${ }^{14} 32$ 39-41 43 Although no single study detected a significant excess of brain cancer, the consistent pattern of non-significant excesses across cohorts for this outcome deserves further investigation (see online supplementary appendix table 6). Animal studies have shown that the brain is a target organ for uranium effects, ${ }^{44-46}$ although, to the best of our knowledge, no animal study has specifically focused on brain or central nervous system cancers.

Only one other cohort of uranium fuel cycle workers reported a non-significant excess of skin cancer so far. ${ }^{14}$ Only three studies reported non-significant excesses of breast cancer ${ }^{1415} 18$ and in two of them, the excess was only observed in women monitored for internal contamination. 1518

\section{Strengths and limitations}

The TRACY cohort has major strengths, such as its large size and excellent quality of follow-up. It is one of the rare cohorts of uranium fuel cycle workers in the world. However, the present study also has some limitations. No individual data on causes of death were available before 1968 due to the late introduction of the French mortality registry. This limitation applies to all epidemiological studies in France. Uranium-related activities began as early as 1959 in some companies included in TRACY. However, the gap in temporal overlap before year 1968 could not hamper the detection of potential excess of diseases occurring after a long latency time following occupational exposure (eg, solid cancers are usually considered to occur after 10 or more years following radiation exposure). Similarly, the fact that occupational data have not been collected after year 2006 so far, although the mortality analysis covered the period 19682008 , is unlikely to generate a substantial impact on the analysis of diseases with long latency times. However, the possible impact of the aforementioned lack of temporal overlap is less clear for diseases with shorter latency times, such as leukaemia. In addition, although the use of mortality data is very informative, it does not allow capturing the full range of possible health effects of uranium exposure, for instance, cognitive, reproductive effects or kidney damage. ${ }^{11}$ More generally, it does not adequately capture the incidence of diseases that are rarely fatal.

The criteria for inclusion into the TRACY cohort guarantees that all permanent staff workers potentially exposed to uranium as part of the upstream steps of the French nuclear fuel cycle (except miners and millers) are included. However, it is clear that some workers not exposed to uranium are also included in the cohort. Having these workers in the cohort will be useful to constitute an internal reference group, when associations between uranium exposure and mortality will be studied. However, further work is still needed (especially a detailed reconstruction of bioassay record histories) before being able to separate all workers exposed from those non-exposed to uranium in the entire TRACY cohort. Complex changes in industrial processes combined with changes in individual job histories make it a long-term task.

However, as a preliminary approach, we explored the hypothesis of different health effects according to different parts of the uranium cycle, by conducting a first analysis by groupings of companies involved in the three main steps of the uranium cycle (conversion, enrichment and fuel manufacturing). We failed to demonstrate potential differences, possibly because of the lack of statistical power and inclusion of non-exposed workers in each group.

\section{Perspectives}

The reconstruction of the multiple exposures of the workers in the TRACY cohort represents a necessary effort to assess risks according to different levels of exposure to uranium, while taking into account other sources of radiation (external exposure to X-ray and gamma rays, and internal contamination with radionuclides such as, for instance, uranium decay products, plutonium and tritium) and other potential risk factors, including carcinogenic, mutagenic or toxic to reproduction chemicals, heat, noise and shift work. Uranium exposure is being reconstructed by a dual approach combining individual monitoring data ${ }^{47}$ and specific job-exposure matrices. ${ }^{38}$ Job exposure matrices allow estimating exposures not covered by any individual monitoring and document uranium compounds present at each job. This detailed exposure reconstruction will allow us to distinguish more finely the different steps of the uranium fuel cycle and therefore better characterise the physicochemical characteristics of the different uranium compounds (in term of solubility and isotopy) to which workers were exposed.

The calculation of uranium concentrations in the target organs of uranium (eg, lungs, kidneys, bones and brain, among others) but also of resulting absorbed radiation doses to these same organs, will help in disentangling chemical from radiation effects of uranium 
exposure. This specific investigation will be possible since separate populations of workers have been exposed to uranium of different isotopic compositions, which show contrasted specific activity $(\mathrm{eg}, 0.33 \mu \mathrm{Ci} / \mathrm{g}$ for depleted uranium, $0.68 \mu \mathrm{Ci} / \mathrm{g}$ for natural uranium and up to $50 \mu \mathrm{Ci} / \mathrm{g}$ for enriched uranium). Since depleted uranium has a very low specific activity, an estimate of the relationship between depleted uranium concentrations in organs and health risks will almost purely assess the potential chemical toxicity of uranium. Beside this, workers exposed to a same level of uranium concentration in organs will receive different internal radiation dose from this nuclide, depending on whether they were exposed to depleted, natural or enriched uranium (again, because of their varying specific activities). Comparing risks in workers exposed to uranium of different isotopic compositions will therefore provide an opportunity to isolate and quantify the radiological component of uranium toxicity. Last, information on risk factors such as tobacco smoking and various clinical parameters (body mass index, blood pressure, lipid profile, etc) is being collected from the occupational health services, ${ }^{48}$ which will allow controlling for their potential confounding effects in future analyses.

The TRACY cohort is still young, with an average age of 60 years, and only $17 \%$ of workers were deceased at the end of follow-up. The statistical power available to study rare or specific diseases (eg, specific cancer sites) will remain limited in this cohort as well as in other cohorts of nuclear fuel cycle workers, unless large excesses actually occur (as was observed in TRACY, for pleural mesothelioma). Extended follow-up and pooled analyses of these cohorts, including TRACY, are needed to produce more statistically precise estimates, which will allow drawing more robust conclusions on possible excess for these diseases and their association with uranium exposure. A pooling of TRACY with other cohorts of uranium workers and miners in Europe is planned, according to harmonised methodologies defined as part of the European project CURE. ${ }^{20}$ In the future, this approach could be extended to cohorts outside Europe.

\section{CONCLUSION}

This first mortality study of the TRACY cohort of French uranium cycle workers has shown a substantial mortality deficit for all broad groupings of causes of death and most of the pathologies studied. However, a significant excess of malignant pleural mesothelioma was also observed and non-significant excesses were observed for a few specific cancer sites. To go further in the investigation of uranium-related risks in this new cohort, collection of individual information on internal uranium exposure as well as other risk factors is underway.

Finally, through the pooling of TRACY with other cohorts of uranium workers, the TRACY cohort will help to improve the knowledge of the health effects of uranium exposure and more generally of internal contaminations by radionuclides, in support of radiation protection research and practice.

Acknowledgements The authors would like to thank all the persons who contributed to the construction of the cohort, from the Administrative, Health and Security Departments of the AREVA plants.

Contributors ES launched the study, obtained the permissions, collected necessary data, ensured data management, performed the analysis and wrote the first draft of the article. IP gathered the vital status and causes of deaths from the national French registries, helped in data management of the cohort and prepared the programmes for the mortality analysis. $\mathrm{DL}$ and $\mathrm{OL}$ contributed to the design of the study and the interpretation of the results. OL supervised the writing of the article. SZ and DBR brought substantial contributions to the analysis of the data and the improvement of the article, particularly in the discussion section, tables and figures. PL and A-PS managed liaison with the AREVA plants and provided access to data sources needed for the construction of the database.

Funding This work was supported by the IRSN and AREVA (bilateral collaborative agreement in epidemiology research), with partial financial support from the European Commission (EURATOM FP7 Grant Number 249689; DoReMi CURE project).

Competing interests A-PS and PL have been employed by AREVA. They provided access to data sources needed for the construction of the database and had a role in launching and supporting the study. A-PS and PL had no influence on the study design, the analysis of the data or the interpretation of the results.

Ethics approval French Data Protection Authority (CNIL) —agreement number DR-2012-611.

Provenance and peer review Not commissioned; externally peer reviewed.

Data sharing statement No additional data are available.

Open Access This is an Open Access article distributed in accordance with the Creative Commons Attribution Non Commercial (CC BY-NC 4.0) license, which permits others to distribute, remix, adapt, build upon this work noncommercially, and license their derivative works on different terms, provided the original work is properly cited and the use is non-commercial. See: http:// creativecommons.org/licenses/by-nc/4.0/

\section{REFERENCES}

1. United Nations Scientific Committee on the Effects of Atomic Radiation. UNSCEAR 2006 Report to the General Assembly with Scientific Annexes, Effects of lonizing Radiation. Vol. 1: Report and Annexes $A$ and $B$. New York: United Nations, 2008.

2. National Research Council. Health risks from exposures to low levels of ionizing radiation (BEIR VII), phase 2. Board on radiation effects research. Washington DC: National Academies Press, 2006.

3. High Level and Expert Group. HLEG Report on European Low Dose Risk Research. EUR 23884. Luxembourg, UK: Office for Official Publications of the European Communities, 2009.

4. Little MP, Azizova TV, Bazyka D, et al. Systematic review and meta-analysis of circulatory disease from exposure to low-level ionizing radiation and estimates of potential population mortality risks. Environ Health Perspect 2012;120:1503-11.

5. Laurier D, Guseva Canu I, Baatout S, et al. DoReMi workshop on multidisciplinary approaches to evaluating cancer risks associated with low-dose internal contamination. Radioprotection 2012;47:119-48.

6. Rage E, Vacquier B, Blanchardon E, et al. Risk of lung cancer mortality in relation to lung doses among French uranium miners: follow-up 1956-1999. Radiat Res 2012;177:288-97.

7. Ostroumova E, Gagniere B, Laurier D, et al. Risk analysis of leukaemia incidence among people living along the Techa River: a nested case-control study. J Radiol Prot 2006;26:17-32.

8. Kesminiene A, Evrard AS, Ivanov VK, et al. Risk of thyroid cancer among chernobyl liquidators. Radiat Res 2012;178:425-36.

9. Gilbert ES, Sokolnikov ME, Preston DL, et al. Lung cancer risks from plutonium: an updated analysis of data from the Mayak worker cohort. Radiat Res 2013;179:332-42. 
10. International Commission on Radiological Protection. The 2007 Recommendations of the International Commission on Radiological Protection. ICRP Publication 103. Ann. ICRP 37 (2-4). 2007.

11. Brugge $D$, Buchner V. Health effects of uranium: new research findings. Rev Environ Health 2011;26:231-49.

12. McGeoghegan D, Binks $K$. The mortality and cancer morbidity experience of workers at the Capenhurst uranium enrichment facility 1946-95. J Radiol Prot 2000;20:381-401.

13. Mc Geoghegan D, Binks K. The mortality and cancer morbidity experience of workers at the Springfields uranium production facility, 1946-95. J Radiol Prot 2000;20:111-37.

14. Loomis DP, Wolf SH. Mortality of workers at a nuclear materials production plant at Oak Ridge, Tennessee, 1947-1990. Am J Ind Med 1996;29:131-41.

15. Boice JD Jr, Cohen SS, Mumma MT, et al. Updated mortality analysis of radiation workers at Rocketdyne (Atomics International), 1948-2008. Radiat Res 2011;176:244-58.

16. Guseva Canu I, Zhivin S, Garsi JP, et al. [Effects of chronic uranium internal exposure on mortality: results of a pilot study among French nuclear workers]. Rev Epidemiol Sante Publique 2014;62:339-50.

17. Chan C, Hughes TS, Muldoon S, et al. Mortality patterns among Paducah Gaseous Diffusion Plant workers. J Occup Environ Med 2010:52:725-32.

18. Gillies M, Haylock R. The cancer mortality and incidence experience of workers at British Nuclear Fuels plc, 1946-2005. J Radiol Prot 2014:34:595-623.

19. Zhivin S, Laurier D, Guseva Canu I. Health effects of occupational exposure to uranium: do physicochemical properties matter? Int $J$ Radiat Biol 2014:11:1-33.

20. Laurent O, Gomolka M, Haylock R, et al. DoReMi-Low Dose Research towards Multidisciplinary Integration. D5.17: Report for an integrated (biology-dosimetry-epidemiology) research project on occupational Uranium exposure. Task5.8: Concerted Uranium Research in Europe (CURE). Final report. 2015

21. Guseva Canu I, Garsi JP, Caer-Lorho S, et al. Does uranium induce circulatory diseases? First results from a French cohort of uranium workers. Occup Environ Med 2012;69:404-9.

22. Guseva Canu I, Jacob S, Cardis E, et al. Uranium carcinogenicity in humans might depend on the physical and chemical nature of uranium and its isotopic composition: results from pilot epidemiological study of French nuclear workers. Cancer Causes Control 2011;22:1563-73.

23. Rage E, Caer-Lorho S, Drubay D, et al. Mortality analyses in the updated French cohort of uranium miners (1946-2007). Int Arch Occup Environ Health 2015;88:717-30.

24. Metz-Flamant C, Laurent O, Samson E, et al. Mortality associated with chronic external radiation exposure in the French combined cohort of nuclear workers. Occup Environ Med 2013;70:630-8.

25. Vrijheid M, Cardis E, Blettner M, et al. The 15-Country Collaborative Study of Cancer Risk Among Radiation Workers in the Nuclear Industry: design, epidemiological methods and descriptive results. Radiat Res 2007:167:361-79.

26. Liddell FD. Simple exact analysis of the standardised mortality ratio. $J$ Epidemiol Community Health 1984;38:85-8.

27. IARC Working Group on the Evaluation of Carcinogenic Risks to Humans. Tobacco Smoke and involuntary smoking. IARC Monogr Eval Carcinog Risks Hum 2004:83:1-1438.

28. Baillargeon J. Characteristics of the healthy worker effect. Occup Med 2001;16:359-66.

29. Zhivin S, Guseva Canu I, Samson E, et al. Mortality (1968-2008) in a French cohort of uranium enrichment workers exposed to soluble uranium. Occup Environ Med 2016;73:167-74.
30. Richardson DB, Keil AP, Tchetgen Tchetgen E, et al. Negative control outcomes and the analysis of standardized mortality ratios. Epidemiology 2015;26:727-32.

31. Pinkerton LE, Bloom TF, Hein MJ, et al. Mortality among a cohort of uranium mill workers: an update. Occup Environ Med 2004;61: $57-64$

32. Kreuzer M, Dufey F, Laurier D, et al. Mortality from internal and external radiation exposure in a cohort of male German uranium millers, 1946-2008. Int Arch Occup Environ Health 2015;88:431-41.

33. Liddell FDK, Miller K. Epidemiology of Mesothelioma Mineral fibers and health. CRC Press, 1991:149-50.

34. Arveux P, Brochard P, Rolland P, et al. Estimation provisoire de l'incidence nationale du mésothéliome pleural à partir du Programme national de surveillance du mésothéliome. Année 1998. Bulletin Epidémiologique Hebdomadaire 2002;3:11-13.

35. Pinheiro GA, Antao VC, Bang KM, et al. Malignant mesothelioma surveillance: a comparison of ICD 10 mortality data with SEER incidence data in nine areas of the United States. Int $J$ Occup Environ Health 2004;10:251-5.

36. Metz-Flamant C, Guseva Canu I, Laurier D. Malignant pleural mesothelioma risk among nuclear workers: a review. J Radiol Prot 2011;31:9-23

37. Metz-Flamant C, Samson E, Caer-Lorho S, et al. Solid cancer mortality associated with chronic external radiation exposure at the French atomic energy commission and nuclear fuel company. Radiat Res 2011:176:115-27.

38. Guseva Canu I, Paquet F, Goldberg M, et al. Comparative assessing for radiological, chemical, and physical exposures at the French uranium conversion plant: is uranium the only stressor? Int $J$ Hyg Environ Health 2009;212:398-413.

39. Dupree-Ellis E, Watkins J, Ingle JN, et al. External radiation exposure and mortality in a cohort of uranium processing workers. Am J Epidemiol 2000;152:91-5.

40. Boice JD Jr, Cohen SS, Mumma MT, et al. A cohort study of uranium millers and miners of Grants, New Mexico, 1979-2005. $J$ Radiol Prot 2008;28:303-25.

41. Zablotska LB, Lane RS, Frost SE. Mortality (1950-1999) and cancer incidence (1969-1999) of workers in the Port Hope cohort study exposed to a unique combination of radium, uranium and gamma-ray doses. BMJ Open 2013;3:e002159.

42. Silver SR, Bertke SJ, Hein MJ, et al. Mortality and ionising radiation exposures among workers employed at the Fernald Feed Materials Production Center (1951-1985). Occup Environ Med 2013;70: 453-63.

43. Boice JD, Cohen SS, Mumma MT, et al. Mortality among radiation workers at Rocketdyne (Atomics International), 1948-1999. Radiat Res 2006;166:98-115.

44. Lestaevel P, Houpert P, Bussy C, et al. The brain is a target organ after acute exposure to depleted uranium. Toxicology 2005;212:219-26.

45. Dinocourt C, Legrand M, Dublineau I, et al. The neurotoxicology of uranium. Toxicology 2015;337:58-71.

46. Shaki F, Hosseini MJ, Ghazi-Khansari M, et al. Depleted uranium induces disruption of energy homeostasis and oxidative stress in isolated rat brain mitochondria. Metallomics 2013;5: 736-44.

47. Blanchardon E, Flüry-Herard A, Paquet F. [The methods and limitations of dosimetry after internal contamination]. Radioprotection 2007;42:501-17.

48. Garsi JP, Samson E, Chablais L, et al. Half-century archives of occupational medical data on French nuclear workers: a dusty warehouse or gold mine for epidemiological research? Arh Hig Rada Toksikol 2014;65:407-16 